\title{
sciendo
}

CIVIL AND ENVIRONMENTAL ENGINEERING REPORTS

E-ISSN 2450-8594

CEER 2019; 29 (2): 060-073

DOI: $10.2478 /$ ceer-2019-0017

Original Research Article

\section{EFFECT OF COCKELE SHELLS ON MORTARS PERFORMANCE IN EXTREME CONDITIONS}

\author{
Assia ABDELOUAHED ${ }^{1 *}$, Houria HEBHOUB ${ }^{1}$, Leila KHERRAF ${ }^{1}$, \\ Mouloud BELACHIA ${ }^{2,3}$ \\ ${ }^{1}$ Department of Civil Engineering, University Of 20 Août 1955 Skikda, Algeria \\ ${ }^{2}$ LMGHU Laboratory, University Of 20 Août 1955 Skikda, Algeria \\ ${ }^{3}$ Department of Civil Engineering and Hydraulic, University of 8 Mai 1945, Guelma
}

\begin{abstract}
This paper studies the use of cockle shell as supplementary cementitious materials SCMs as substitute for cement. The cockle shells generally have a high $\mathrm{CaO}$ content which can alter the behavior and the properties of mortars and concrete. Cockle shell is used with weight ratios of 5, 10, 15 and $20 \%$ to formulate a mortar with cockle shell and a control mortar CM with $0 \%$ of cockle shell. The properties in the fresh state, the mechanical strength and the weight loss test as well as the depth of penetration of each mixture were carried out through the conducted experiments. Consistency and density of fresh mortars were determined, the results obtained showed that cockle shell have a significant influence on the properties of mortars in the fresh state.

The different results of hardened mortars show that the introduction of cockle shell tends to accelerate the development kinetics of strength at the young age but its ratio cannot be above of $5 \%$. Mortar with $10 \%$ presented the lower depth penetration, the loss weight increased proportionally with the increasing of cockle shell amount.
\end{abstract}

Keywords: shells, cement, strength, properties, durability

\footnotetext{
${ }^{1 *}$ Corresponding author: Po Box 26, Road of el Hadeik, Skikda, Algeria 2100, e-mail: a.zbdelouahed@univ-skikda.dz
} 


\section{INTRODUCTION}

The use of waste and by product materials instead of raw materials in cement and concrete mixture was the best process to achieve the development of the concrete industry [1]. In order to reduce the dependency on virgin materials for construction, efforts have been made to incorporate by-products and wastes from different industries as alternatives in concrete. The search for a supplementary cementitious materials (SCMs) has become a major concern for the manufacture of cements, recently several researchers have been proven that the use of SCMs improve mechanical performances and durability of cements [2].

One of potential waste material that is available in nature is waste seashells. There are several types of waste seashell available, such as cockle shells, oyster shells, mussel shells, scallop shells. Every year about 10 million tons of shells are disposed of in landfills in China, which is the largest shellfish producer in the world [3]. In France 160,000 tons of seashells are produced by shellfish farming industry and about 45,000 tons of shellfish per year from fishing [4].

When seashell wastes left for a long time, it can lead to microbial decomposition of salts into gases like hydrogen sulphide, and ammonia which are very harmful to nature [5]. The use of seashell in concrete is studding by a few researchers, Pusit Lertwattanaruk et al. [6] used ground seashells as supplementary cementitious materials, their results indicated that ground seashells can be applied as a SCMs in mortars, they found that mortars with ground seashells present an adequate strength, less shrinkage with drying and lower thermal conductivity compared to the control mortar.

Wen-Ten Kuo et al. [7], and Gil-Lim Yoon et al. [8] used the waste oyster shells as replacement in sand, they showed that oyster shells can be resources in replacement of sand, their results demonstrated that there was no significant reduction in the compressive strength up to $20 \%$ [7] and $40 \%$ [8] of dosages of waste oyster shells sand instead of sand. Monita Olivia et al. [1] also used ground cockle shell as SCMs, they found that the compressive strength has been an optimum value by $4 \%$ of replacement, while the tensile strength and flexion have been shown better results with the seashell concrete. Dang Hanh Nguyen et al. [9] found that the crushed seashells can be used as a replacement in the previous concrete composition, for low-volume roads, they showed that an acceptable durability of pervious concrete with and without crushed shells for the application of low traffic load. According to Monita Olivia et al. [10], the substitute of the Portland cement with the ground cockle shell and clam shell influenced in physical and mechanical properties of the concrete, the OPC cockle concrete showed lower setting time, density and tensile strength than the OPC concrete. E.I. Yang et al. [11] studied the durability of concrete with oyster seashell partially substituted for fine aggregate. They noted that, the strength, the freeze thaw 
resistance, drying shrinkage, and permeability are significantly affected by the increase of oyster seashell content, essentially for long-term, while carbonation and chemical attack were not substantially affected. Carolina Martínez-García et al. [12] use the mussel shell as fine aggregate in concrete, they proved that weight loss increases even in small percentage, the increase in weight loss is related to the high-water absorption of mussel shell aggregate in comparison with natural sand.

Yang et al. [13] found that the workability of the concrete, decreased when the substitution rate of oyster shell increased, they used oyster shell as fine aggregate replacement in concrete.

The work presented in this paper aims to valorise the use of cockle shells and demonstrate that it can be reused as SCMs as substitute for cement, based on their chemical and mechanical properties, studying their effect on mechanical and chemical performance of different mortars.

\section{MATERIALS}

Natural sand class 0/2 from Felfela, Skikda, Algeria is used to make mortar mixtures complied with NF EN-196-1, with a specific gravity of 2.53; the sand equivalent value is $79.59 \%$ and fineness modulus of 3.30 .

The Ordinary Portland cement type I CEMI 42.5 was used as a binder, it is delivered by the cement company of Ain Kbira Company (setif) Algeria. It has a density of 3.07 and the Blaine surface area is about $3700 \mathrm{~cm}^{2} / \mathrm{g}$.

The cockle shells were collected from the beach of Guerbaz region of Skikda Algeria. The cockle shells were cleaned, dried, crushed into small pieces using a crusher and grinding in a standardized ball mill with a capacity of $10 \mathrm{~kg}$. After its preparation for use in this experiment, its specific surface was about $6550 \mathrm{~cm}^{2} / \mathrm{g}$, and has a specific gravity of 2.98 . The chemical composition of cockle shell powder and cement are shown in Table1. Cockle shells are introduced as a SCMs cement substitute.

Potable water was used in all the mixes and curing of the specimens.

Tab.1. The chemical composition of cockle shell powder and cement

\begin{tabular}{|c|c|c|c|}
\hline Designations & Sand 0/2 & CEMI 42.5 & Cockle shell \\
\hline $\mathrm{CaO}$ & 0.41 & 65.85 & 53.63 \\
\hline $\mathrm{Al}_{2} \mathrm{O}_{3}$ & 1.32 & 4.13 & 0.29 \\
\hline $\mathrm{Fe}_{2} \mathrm{O}_{3}$ & 0.62 & 4.16 & 0.15 \\
\hline $\mathrm{SiO}_{2}$ & 96.35 & 21.31 & 0.74 \\
\hline $\mathrm{MgO}_{\mathrm{Na}} \mathrm{O}$ & 0.07 & 1.34 & 0.22 \\
\hline $\mathrm{K}_{2} \mathrm{O}$ & 0.05 & 0.16 & 0.180 \\
\hline $\mathrm{Cl}^{-}$ & 0.39 & 0.25 & 0.020 \\
\hline $\mathrm{SO}_{3}$ & 00.00 & 0.003 & 0.000 \\
\hline & 00.00 & 2.13 & 0.05 \\
\hline
\end{tabular}




\begin{tabular}{|c|c|c|c|}
\hline $\mathrm{MS}$ & -- & 2.43 & -- \\
\hline $\mathrm{MAF}$ & -- & 0.88 & -- \\
\hline $\mathrm{C}_{3} \mathrm{~S}$ & -- & 72.25 & -- \\
\hline $\mathrm{C}_{2} \mathrm{~S}$ & -- & 8.83 & -- \\
\hline $\mathrm{C}_{3} \mathrm{~A}$ & -- & 3.14 & -- \\
\hline $\mathrm{C}_{4} \mathrm{AF}$ & -- & 14.7 & -- \\
\hline
\end{tabular}

\section{TEST AND MIXING PROCEDURES}

Test specimens of mortar were prepared according to the standard EN196-1 [14]. All mixtures are fixed the same ratio water on cement W/C by 0.57 .

The test specimens used for the compressive strength test, Flexion strength test, and immersion absorption test and chloride penetration had dimensions of $4 \times 4 \times 16 \mathrm{~cm}$ and those used for the weight loss test had dimensions of $5 \times 5 \times 5 \mathrm{~cm}$. Cockle shells powders were used to partially replace cement in the mortar at replacement weight ratios of 5, 10, 15 and 20\%. A control mortar (CM) specimen $(0 \%$ of cockle shell) was used as a reference. Three specimens were used for each age. Specimens produced from fresh mortar were remolded after $24 \mathrm{~h}$ and were then cured in water at $20 \pm 2{ }^{\circ} \mathrm{C}$ until the date of the test.

\section{RESULTS AND DISCUSSIONS}

\subsection{Consistency of mortars}

The slump and the density of various mortars are evaluated according to the standard NF EN 1015-3 and NF EN 1015-6 respectively [15,16] The results of consistency and density of CM and mortars with cockle seashells are shown in Fig. 1 and Fig. 2.

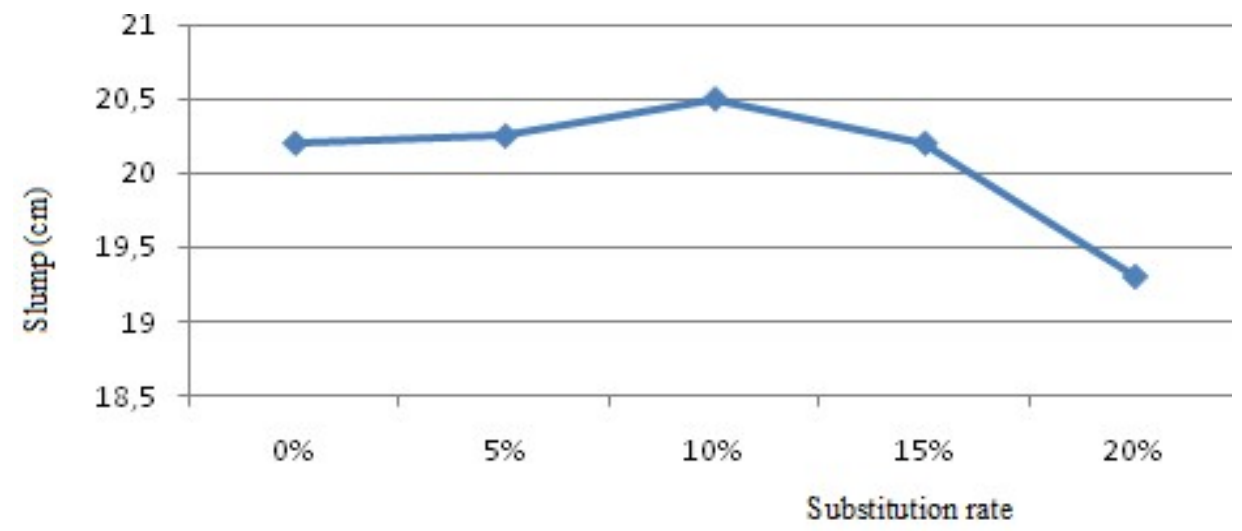

Fig. 1. Consistency of mortars containing cockle shell 
There was a slight increase of slump values with increasing percentage of cockle -shells until $10 \%$, the replacement of cement with ground seashells decreased the amount of cementitious material and increased the free water content in the mix. Beyond $10 \%$ the slump values were turn to decrease. The water requirement of cockle shell became higher owing to its relatively high specific surface area of the binder (cement + cockle shell) [9].

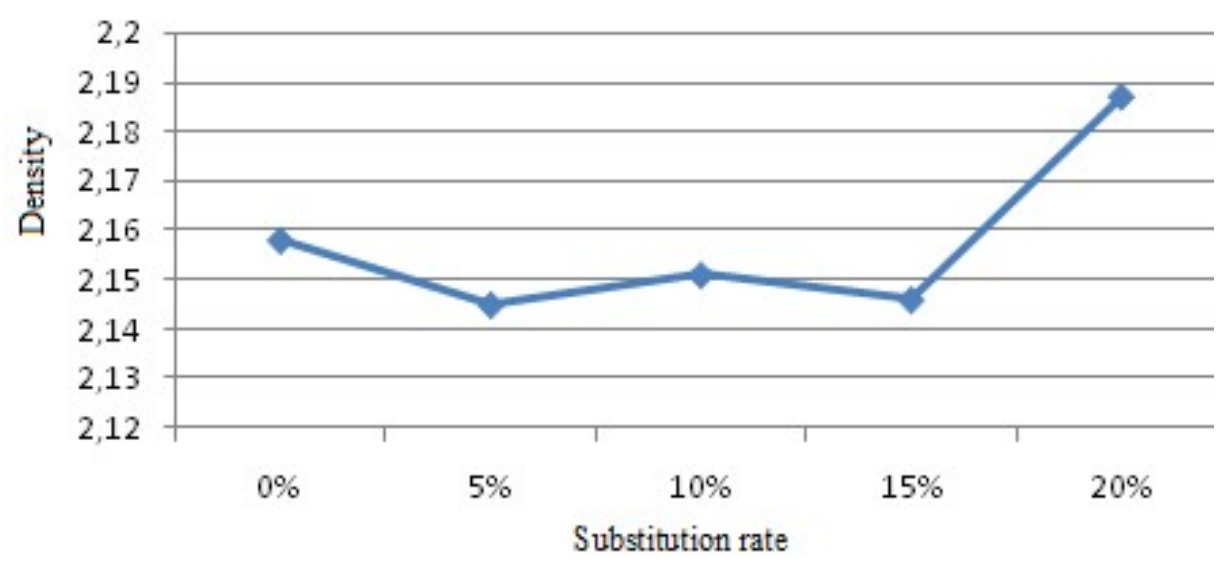

Fig. 2. Density of mortars containing cockle shell

From Fig. 2, we can observe that the density of the mortars was not stable; the density was diminished with a low substitute of cockle shell (5\%), and then returned to increase in a lean way. The mortar with $15 \%$ of cockle shell had a density similar to the mortar 5\% cockle shell, beyond $15 \%$ of cockle shell the density increased of a significant way, the mortar $20 \%$ shell had a density 2,189 which presented the highest density.

\subsection{Compressive and flexural tensile strength of mortars}

After 2, 7, 28 and 90 days of water curing, the $4 \times 4 \times 16 \mathrm{~cm}$ samples were used for compressive and flexural tensile strength tests. The results are shown in Fig. 3 and Fig. 4, respectively.

According to the results obtained (Fig. 3), we observe that the compressive strength of all mortars studied, increases regularly with age and shows no fall until the 90 days. Increasing the percentage replacement of cockle shell, tended to reduce the compressive strength of the mortars, because of the less reactive material of cockle shell mixed with the Portland cement and the reduction of the reactive part exists in the cement. At early age ( 2 days) mortar with $5 \%$ of cockle shell showed the best compressive and flexural tensile strength, it can be attributed to the height Blaine surface area of cockle shell. The mortars with 10\% 
and $15 \%$ showed a similar compressive strength to $\mathrm{CM}(0 \%)$. At 28 and 90 days compressive strength of mortars with $5 \%$ of cockle shell falling back in comparison with compressive strength of $\mathrm{CM}$, this was likely due to a decrease of the cement content that could reduce the rate of hydration in mortar.

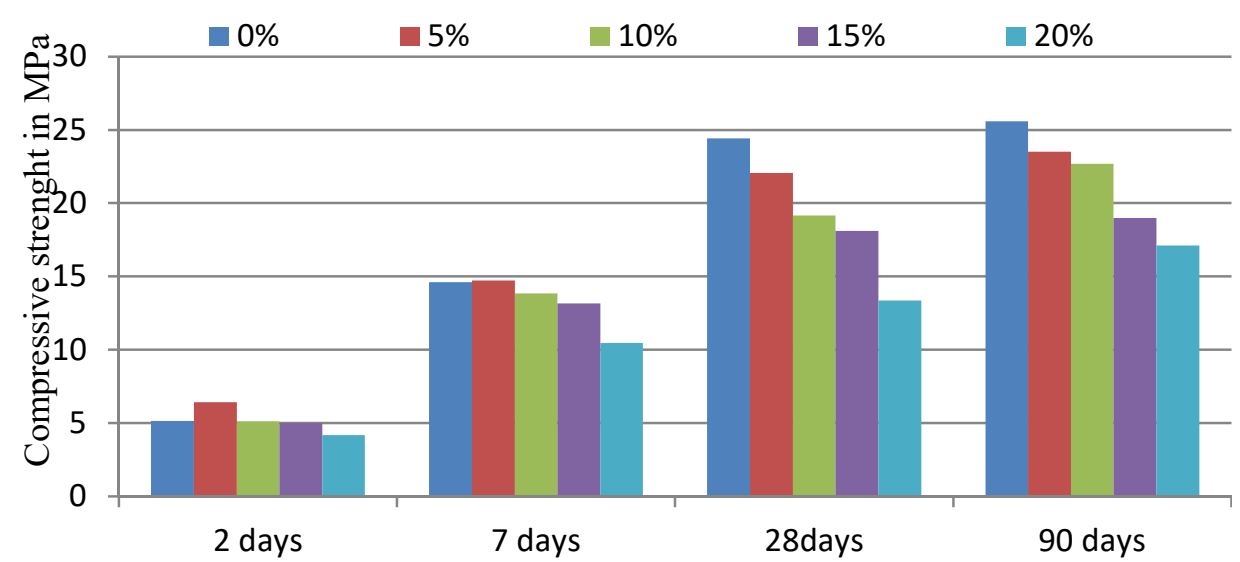

Fig. 3. Effect of the substitution rate on the compressive strength

It must be noted that cockle shell increase compressive strength at early age and the percentage of cockle shell must limited to $5 \%$ or less, Monita, olivia et al. found that the compressive strength has been an optimum value of $4 \%$ of replacement [1].

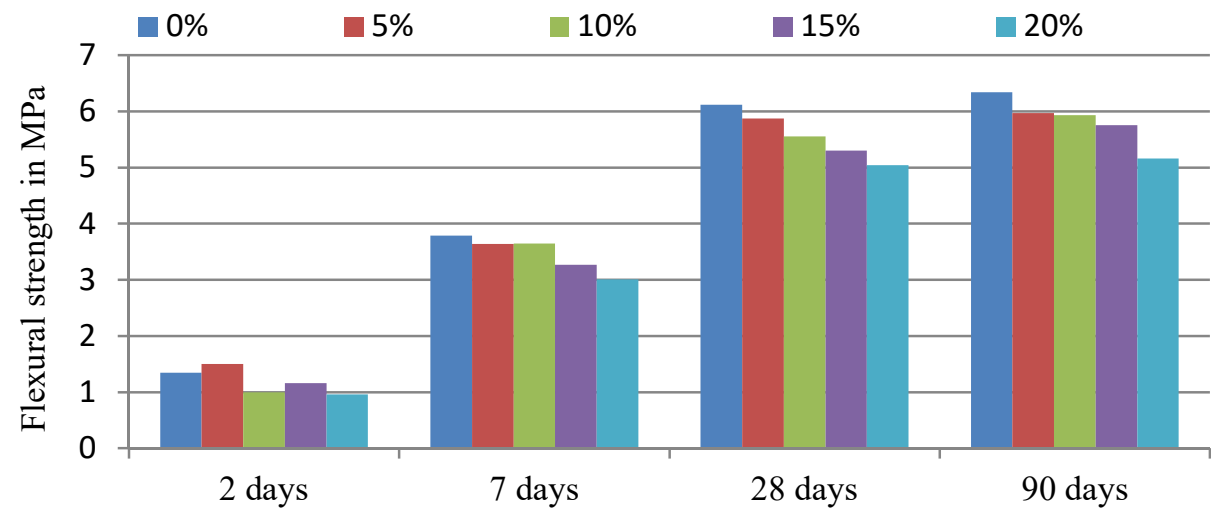

Fig. 4. Effect of the substitution rate on the flexural strength 
The illustrated results of the flexural strength test (Fig. 4) show similar tendencies to compressive strength. However, the flexural strengths of mortars with $5 \%$ of cockle shell were low compared to those of the control mortar at 7 days. In the long term (at 28 and 90 days) the flexural strength decreases with increasing cockle shell content.

\subsection{Water absorption test}

To determine the water absorption of different mortar specimens, three specimens from each mortar were dried at a temperature of $105^{\circ} \mathrm{C}$ and its weight determined as initial weight. Then the samples were immersed in water for 24 hours and its saturated surface dry weight was recorded as the final weight. Water absorption of specimens is reported as the percentage increase in weight. It was determined by the formula:

$$
A b s=\frac{M w-M d}{M d}
$$

Where Mw, is weight of specimen after immersion in water and Md, Weight of specimen after drying.

The results of water absorption are presented in Fig. 5.

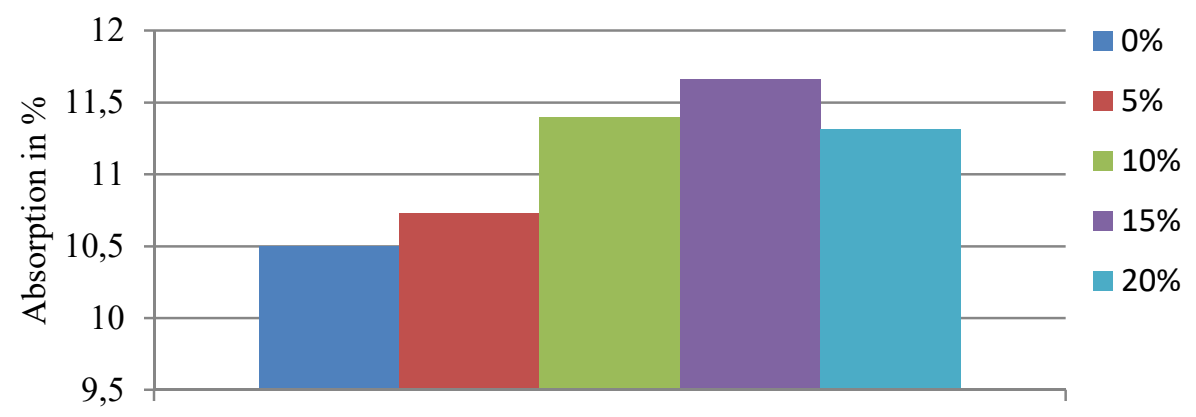

Fig. 5. Effect of substitution rate on water absorption variation

When the ratio of replacement of cockle shell in cement increased, there was an increase in water absorption, due to the height porosity of specimens with cockle shell. Until the ratio of $20 \%$ where water absorption percentage decreased, this is due to the reduced volume of capillary voids caused by the high compactness of cockle seashell mortar. In fact, in the case of cockle shell, capillary voids in the mortar are more important, which facilitates the development of new products during the hydration of cement. 


\subsection{Chloride penetration}

After 28 days of water curing, specimens $4 \times 4 \times 16 \mathrm{~cm}$, were stored in sodium chloride solution with the concentration of $5 \%$. At certain deadlines $(28,56$ and 90 days), the samples are removed from the solution and split in two parts. The depth of chloride penetration is measured on fresh fractures using a colored indicator. The aggressive solution was renewed every 28 days.

The measurement of the depth of chloride penetration is carried out using a sputtering of the colored indicator: $\mathrm{AgNO}_{3}$ silver nitrate $(\mathrm{V})$ on the faces of the rupture test specimen.

After spraying the $\mathrm{AgNO}_{3}$, if chlorides are present in the interstitial phase of the sample, two zones of different colors appear. The zone containing free chlorides (that is to say, soluble in water) will appear in light color and the zone containing none, of dark color. Indeed, when spraying the reagent, the chemical reaction between the chlorides present and the silver is characterized by the appearance of a white precipitate $(\mathrm{AgCl})$. The depth of chloride penetration is therefore the distance between the surface and the line of separation between the two different color areas.

The results of depths of chloride penetration are presented in Fig. 6 .

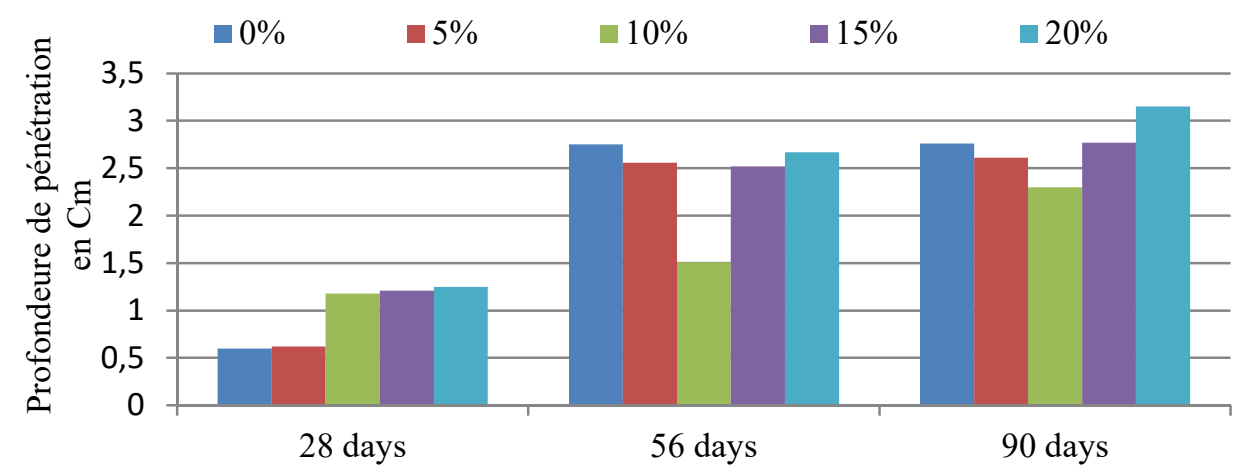

Fig. 6. Chloride penetration depth of mortars according to the age of immersion in $5 \%$ of $\mathrm{NaCl}$

As the $\mathrm{AgNO}_{3}$ colorimetric indicator allows reliable free-chloride penetration detection for different mortars, we can observe that, there is a difference between the results at the age of 28 days and at the age of 56 days, however there are identical results at 56 and 90 days. CM and mortars $5 \%$ of cockle shell have the same depth penetration at 28 days, it means that the addition of $5 \%$ of cockle shell did not affect on mortar to resist chloride penetration. When the replacement of 
cockle seashell increased, chloride penetration also increased. Beyond 28 days, the evolution of the penetration depth is non-stationary which is defined by a nonlinear variation as shown in Fig. 6 above.

At 56 and 90 days mortar with $10 \%$ of cockle shell presented the best resistance to penetration that corresponds to the shallower depth of chloride penetration. The depth penetration of chloride decrease with increasing cockle seashell amount until $15 \%$, higher cement consumption means a higher content of $\mathrm{C}_{3} \mathrm{~A}$ available to help in binding chloride ions, this higher binding capacity reduces the amount of free chlorides, which are those that effectively take part in mass transport [17]. The depth of penetration return to increase with $15 \%$ of cockle shell, the rate of chloride penetration depends on the porosity of the mortars and the pore size distribution. In addition, the difference between the penetration depths could be due to a different mobility of the chlorides inside the pores following their distribution in the cement matrix. It can be also observed that the depth of chloride penetration increased with the age.

\subsection{Weight loss}

After 28 days of water curing, the $5 \times 5 \times 5 \mathrm{~cm}$ specimens were immersed in two solutions, $\mathrm{CH}_{3} \mathrm{COOH}$ and $\mathrm{H}_{2} \mathrm{SO}_{4}$ with the same concentration $5 \%$. The aggressive solutions were renewed every 28 days. After 2, 7, 28, 56 and 90 days, they were used to estimate the weight loss according to the standard ASTMC267-96 [18]

\section{Sulfuric (VI) acid}

Results of the weight changes for the cockle shell mortars preserved in $\mathrm{H}_{2} \mathrm{SO}_{4}$ solution are presented in Fig. 7.

In the specimens immersed in 5\% sulfuric (VI) acid, a sudden loss of weight was noticed during 2 to 90 days. It can be also noted that in early age the loss weight increased proportionally with cockle shell content, the highest value of weight loss corresponds to specimens with $20 \%$ of cockle shell that presented $1.657 \%$, when $\mathrm{CM}$ weight loss was $1.184 \%$ at the age of 7 days.

The weight dropped substantially in all specimens at 28 days. From 56 days specimens with 10, 15 and $20 \%$ of cockle shell had the maximum weight loss, the highest value was presented by mortars with $20 \%$ cockle shell. However, mortar with $5 \%$ of cockle shell exhibited lesser weight loss at all ages until at 90 days where its weight loss was similar to the CM weight loss. 


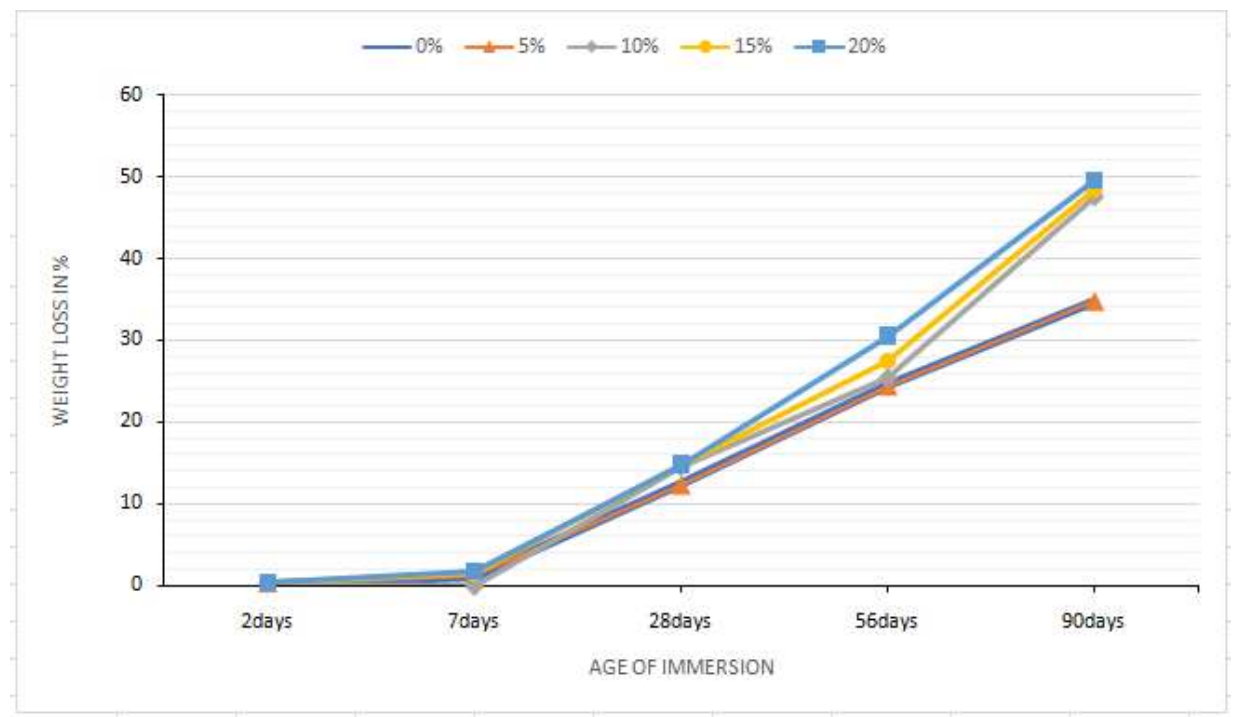

Fig. 7. Weight loss of specimens after 2-7- 28-56-90 days of immersion in $5 \% \mathrm{H}_{2} \mathrm{SO}_{4}$

The different hydrates stability's is variable. However, the most susceptible component in aggressive attack is Portlandite [19]. When the mortars are attacked by sulfuric (VI) acid $\mathrm{H}_{2} \mathrm{SO}_{4}$, they react with the Portlandite $\mathrm{Ca}(\mathrm{OH})_{2}$ resulting from the hydration of the cement, which causes the formation of gypsum and. The process is described by the following chemical reactions:

$$
\begin{gathered}
\mathrm{Ca}(\mathrm{OH})_{2}+\mathrm{H}_{2} \mathrm{SO}_{4} \rightarrow \mathrm{CaSO}_{4} \cdot 2 \mathrm{H}_{2} \mathrm{O} \\
3 \mathrm{CaSO}_{4}+3 \mathrm{CaO} \cdot \mathrm{Al}_{2} \mathrm{O}_{3} \cdot 6 \mathrm{H}_{2} \mathrm{O}+26 \mathrm{H}_{2} \mathrm{O} \rightarrow 3 \mathrm{CaO} \cdot \mathrm{Al}_{2} \mathrm{O}_{3} \cdot 3 \mathrm{CaSO}_{4} \cdot 32 \mathrm{H}_{2} \mathrm{O}
\end{gathered}
$$

\section{Acetic acid $\mathrm{CH}_{3} \mathrm{COOH}$}

The curves, presented by Fig. 8, show the weight loss in \% measured at the end of each aging of mortars stored in acetic acid solution $\mathrm{CH}_{3} \mathrm{COOH}$ (after 28 days of cure in water). Fig. 8 shows that the mass variation is presented by a loss of weight in the acetic acid $\left(\mathrm{CH}_{3} \mathrm{COOH}\right)$.

At 2 days it was observed a loss of weight for all the mortars with approximate values, the mortar with $5 \%$ cockle shell had a lower weight loss about $0.97 \%$ that is the most resistant mortar at an early age. At 7 days the weight loss of CM and mortar with 5\% cockle shell became close, the highest loss corresponds to mortar with $20 \%$ cockle shell, and it can be also observed that the values are close. The replacement of cockle shell by weight in cement at an early stage affected the hydration reaction and resulted in a lower amount of Portlandite $\mathrm{Ca}(\mathrm{OH})_{2}$. For 
those reasons, the reaction between acetic acid and calcium hydroxide ions decreased.

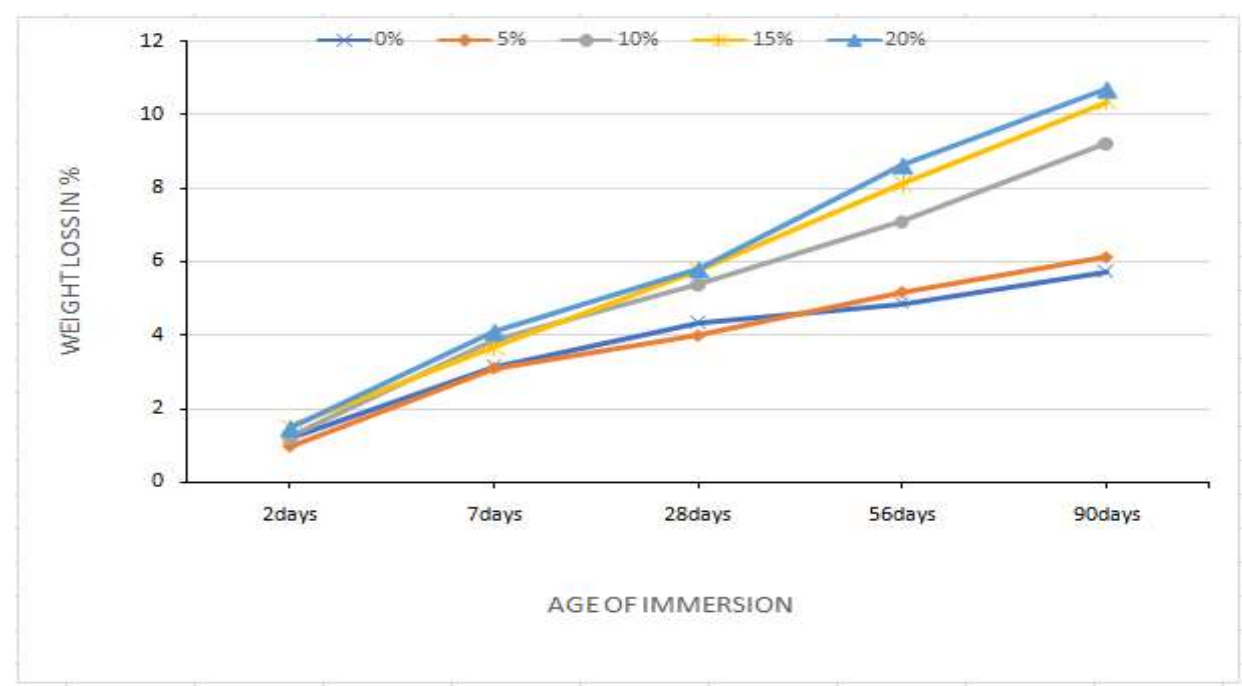

Fig. 8. Weight loss of specimens after 2-7-28-56-90 days of immersion in $5 \% \mathrm{CH}_{3} \mathrm{COOH}$

At the age of 28 days there is an important weight loss corresponds to mortars with 10,15 and $20 \%$ of cockle shell, mortar with $5 \%$ cockle shell presented always the lowest loss weight. At 56 days, the value of loss weight of mortar with $5 \%$ cockle shell has fallen compared with $\mathrm{CM}$ that showed the best results. However, the mortars with 20 and $15 \%$ of cockle seashell always have a loss of weight about 8.63 and $8.12 \%$ respectively. At the age of 90 days, the weight loss continues to increase, and this development has become proportionally of cockle shell content, the best result corresponds by CM. The increased porosity leads to an increase of the free water in the mortar texture [20].

It is well known that acetic acid is very aggressive compounds [21,22]. Their reactivity was explained by the reaction with the Portlandite $\mathrm{Ca}(\mathrm{OH})_{2}$ of the mortar producing very soluble calcium salts [22] which, because of its solubility, are leached away by the aggressive solution. Calcium acetate $\mathrm{Ca}\left(\mathrm{CH}_{3} \mathrm{COO}\right)_{2}$ causes dissolution of cement through the reaction between the Portlandite (calcium hydroxide) and the acetic acid, the reaction was expressed in (3).

$$
\mathrm{Ca}(\mathrm{OH})_{2}+2 \mathrm{CH}_{3} \mathrm{COOH} \rightarrow \mathrm{Ca}\left(\mathrm{CH}_{3} \mathrm{COO}\right)_{2}+2 \mathrm{H}_{2} \mathrm{O}
$$

Calcium acetate

The acid attacks the surface layer of the specimens, and this action leads to weight loss of the immersed specimens. 


\section{CONCLUSION}

As seen from this study, for the reuse of cockle shell, we can draw the following conclusions:

Cockle shell content affects the slump of mortars; the substitution of $10 \%$ of cockle shell shows the highest workability.

The introduction of cockle seashell tends to accelerate the development kinetics of compressive and flexural strength at a young age. The incorporation of 5\% cockle shell has better compressive and flexural strength at a young age ( 2 and 7 days), behind it has a closed strength with $\mathrm{CM}$ at a long-term (28 and 90 days).

Compressive and flexural strength are affected in the same way by the substitution of the cockle shell in the cement.

The test results indicate that the substitution of $10 \%$ of cockle shell into cement reduces the depth penetration at a long-term. This leads to less penetration of chloride ions into the mortar shown in the experiment results.

In terms of weight loss due to the effect of $\mathrm{H}_{2} \mathrm{SO}_{4}$ acid, specimens with $5 \%$ of cockle shell were more resistant to weight loss, beyond this content; the loss will be more severe. The substitution of $5 \%$ of the cockle shell in cement can increase the resistance to chemical attack.

In $\mathrm{CH}_{3} \mathrm{COOH}$ acid, the incorporation of cockle in cement tends to increase the weight loss of all mortars. Mortar with $5 \%$ of cockle shell shows losses close to the control mortar.

$\mathrm{CH}_{3} \mathrm{COOH}$ and $\mathrm{H}_{2} \mathrm{SO}_{4}$ are very harmful for cockle shell mortars. For the same concentration (5\%) of acid, the degree of attack tended to be more severe in sulfuric (VI) acid than in acetic acid.

\section{REFERENCES}

[1] Olivia, M, Mifshella, AA and Darmayanti, L 2015. Mechanical properties of seashell concrete. Procedia Engineering, 125, 760-764.

[2] Abdelouahed, A, Belachia, M and Sebbagh, T 2018. Effect of SCMs on mechanical, chemical and microstructural properties of SRC in acidic medium. European Journal of Environmental and Civil Engineering, 22, 2(212-225.)

[3] Mo, KH, Alengaram, UJ, Jumaat, MZ, Lee, SC, Goh, WI and Yuen, CW 2018. Recycling of seashell waste in concrete: A review. Construction and Building Materials. 162, 751-764.

[4] France Agri Mer 2015. Les filières pêche et aquaculture en France. 36.

[5] Yoon, GL, Kim, BT, Kim, BO and HanS, H 2003. Chemical-mechanical characteristics of crushed oyster-shell. Waste Management, 23, 9, 825-834. 
[6] Lertwattanaruk, P, Makul, N and Siripattarapravat, C 2012. Utilization of ground waste seashells in cement mortars for masonry and plastering. Journal of environmental management, 111, 133-141.

[7] Kuo, WT, Wang, HY, Shu, CY, and Su, DS 2013. Engineering properties of controlled low-strength materials containing waste oyster shells. Construction and Building Materials, 46, 128-133.

[8] Yoon, GL, Kim, BT, Kim, BO and Han, SH 2003. Chemical-mechanical characteristics of crushed oyster-shell. Waste Management, 23,9, 825-834.

[9] Nguyen, DH, Boutouil, M, Sebaibi, N, Baraud, F and Leleyter, L 2017. Durability of pervious concrete using crushed seashells. Construction and Building Materials, 135, 137-150.

[10] Pelisser, F, Zavarise, N, Longo, TA and Bernardin, AM 2011. Concrete made with recycled tire rubber: effect of alkaline activation and silica fume addition. Journal of Cleaner Production, 19, 6-7, 757-763.

[11] Yang, EI, Kim, MY, Park, HG and Yi, ST 2010. Effect of partial replacement of sand with dry oyster shell on the long-term performance of concrete. Construction and building materials, 24, 5, 758-765.

[12] Martínez-García, C, González-Fonteboa, B, Martínez-Abella, F and CarroLópez, D 2007. Performance of mussel shell as aggregate in plain concrete. Construction and Building Materials, 139, 570-583.

[13] Yang, EI, Yi, ST and Leem, YM 2005. Effect of oyster shell substituted for fine aggregate on concrete characteristics: Part I. Fundamental properties. Cement and Concrete Research, 35, 11 (2005), 2175-2182.

[14] NF EN 196-1 (2006, April). Methods of testing cement - Part 1: Determination of strength.

[15] NF EN 1015-3 (2007, May). P12-303/A2. Methods of testing masonry mortars - Part 3: Determination of the consistency of fresh mortar.

[16] NF EN 1015-6/A1 (2007, May). P12-306/A1. Methods of testing masonry mortars - Part 6: Determination of the apparent density of mortars.

[17] Oh, BH and Jang, SY 2007. Effects of material and environmental parameters on chloride penetration profiles in concrete structures. Cement and Concrete Research, 37, 1, 47-53.

[18] ASTM C 267-96 (2001, October). Standard test methods for chemical resistance of mortars, grouts, and monolithic surfacing and polymer concretes.

[19] Oueslati, O, and Duchesne, J 2012. The effect of SCMs and curing time on resistance of mortars subjected to organic acids. Cement and Concrete Research, 42, 1, 205-214.

[20] Bensted, J, and Barnes, P (Eds.) 2002. Structure and performance of cements, London, Spon Press, 641. 
[21] Pavlik, V 1994. Corrosion of hardened cement paste by acetic and nitric acids part I: Calculation of corrosion depth. Cement and concrete research, 24, 3, 551-562.

[22] Zivica, V and Bajza, A 2002. Acidic attack of cement-based materials a review Part 2. Factors of rate of acidic attack and protective measures. Construction and building materials, 16, 215-222.

Editor received the manuscript: 16.06 .2019 